\title{
The changing phenotype of microglia from homeostasis to disease
}

Xiao-Guang Luo ${ }^{1}$ and Sheng-Di Chen ${ }^{2 *}$

\begin{abstract}
It has been nearly a century since the early description of microglia by Rio-Hortega; since then many more biological and pathological features of microglia have been recognized. Today, microglia are generally considered to be beneficial to homeostasis at the resting state through their abilities to survey the environment and phagocytose debris. However, when activated microglia assume diverse phenotypes ranging from fully inflamed, which involves the release of many pro-inflammatory cytokines, to alternatively activated, releasing antiinflammatory cytokines or neurotrophins, the consequences to neurons can range from detrimental to supportive. Due to the different experimental sets and conditions, contradictory results have been obtained regarding the controversial question of whether microglia are "good" or "bad." While it is well understood that the dual roles of activated microglia depend on specific situations, the underlying mechanisms have remained largely unclear, and the interpretation of certain findings related to diverse microglial phenotypes continues to be problematic. In this review we discuss the functions of microglia in neuronal survival and neurogenesis, the crosstalk between microglia and surrounding cells, and the potential factors that could influence the eventual manifestation of microglia.
\end{abstract}

Keywords: Microglia, Neuroprotection, Phenotypes, Senescence, Crosstalk

\section{Table of contents}

I. Introduction

II. The origin of microglia

III.Microlgia the dual natures of neurotoxicity and neuroprotection

IV.Crosstalk between microglia and other brain cells

1. Cross talk between microglia and neurons: neurons as regulators of microglial activation

2. Cross talk between astrocytes and microglia: reciprocal influences

3. Microglia-T cell crosstalk:key determinants for the trend of immune response

V. Whether microglial activation is neurotrophic or neurotoxic is context-dependent

1. Aging can result in microglial dysfunction and subsequent neurotoxicity

2. The timing of activation is an indispensable determinant of microglial function

\footnotetext{
* Correspondence: chen_sd@medmail.com.cn

${ }^{2}$ Department of Neurology \& Institute of Neurology, Ruijin Hospital affiliated to Shanghai Jiao Tong University, Shanghai 200025, China

Full list of author information is available at the end of the article
}

3. Activation states of microglia

4. The stimulus type is another turning point for microglial function

VI. Microglia and neurogenesis

VII.Conclusion

\begin{abstract}
Introduction
Microglia are generally considered the immune cells of the central nervous system (CNS) and account for $10 \%$ of the total glial cell population in the brain. In a normal physiological environment, they work as sentinel cells by continually screening the brain tissue; they actively participate in pathological processes by changing morphology, expressing various antigens and becoming phagocytic. During the past 20 years, thousands of papers have been published describing both the detrimental and beneficial roles of microglia in various brain disorders, from acute infection or stroke to the long and chronic process of neurodegeneration. Microglia have been firmly established as a key cellular component involved in the eventual outcome of inflammation and eventually contribute to the chronic neurodegeneration; The physiology and signaling of microglia have been comprehensively reviewed
\end{abstract}

\section{Biomed Central}

(c) 2012 Luo and Chen; licensee BioMed Central Ltd. This is an Open Access article distributed under the terms of the Creative Commons Attribution License (http://creativecommons.org/licenses/by/2.0), which permits unrestricted use, distribution, and reproduction in any medium, provided the original work is properly cited. 
by Kettenmann's series papers[1-6], however, the regulation of microglial activity is a highly complex system, and the responses of microglia are tailored in a multi-factor dependent manner, and which are the focus we try to review in this paper.

\section{The origin of microglia}

The precise origin and cell lineage of microglia has been a long time debate. So far two most important hypotheses for microglial origin have been held: "neuroectodermal" or "myeloid-monocytic". Even though the latter has been more widely accepted now, the neuroectodermal hypothesis remains interesting. Skoff [7] detected "multipotential glia cell" with a rat model of optic nerve degeneration and optic nerve development, these cells were demonstrated to originate from neuroectodermal matrix cells, and Kitamura later confirmed this result by describing a continuous morphological transition between glioblasts and ramified microglia in the developing gray matter of hippocampus [8]. The hematopoietic origin of microglia also received a lot attention, the presence of bone marrow Mac- 1 positive cells were demonstrated in the brain of embryonic and adult mice, and these cells were proved to be the progenitors for microglial cells [9], also transplantation of GFP + mice bone marrow cells in GFP- host mice revealed the presence of many GFP + microglia throughout developing and/or inflamed CNS [10,11], which strongly suggest the hematopoietic stem cells as one of the origins for replenishment of microglia in the neuropathology. Additionally due to the high similarity in marker expression and phagocytosis behavior between circulating monocytes and microglia, people speculate the monocytic origin of microglia, and a couple of experiments have been performed to show the appearance of labeled monocytes in the developing [12] or inflamed brain [13]. In many cases, the peripheral macrophages are considered to be the orthologue $[14,15]$ or backup of microglia and infiltrate the brain to supplement microglia, thus to some extent peripheral macrophages mirror the behavior of microglia in the brain and Monocytederived Macrophages (MDMs) from patients have been used as a substitute of microglia in many studies [16-18].

\section{Microglia: the dual natures of neurotoxicity and neuroprotection}

Neuroinflammation has long been considered a mediator of secondary damage following a small injury to the CNS. As the primary immune cells in the brain, microglia are expected to take active roles in the damage process. The presence of activated microglia within injured brain regions and in post-mortem tissue from patients having various neurodegenerative disorders has led to the assumption that all reactive microglia contribute to an adverse and degenerative process. Further studies describe destructive roles for microglia by demonstrating the release of a range of neurotoxins from microglia that includes pro-inflammatory cytokines [19-21], nitric oxide [22,23] and reactive oxygen species [24,25]; the inhibition of microglial activation in various experiments results in the attenuation of neurotoxic events and improves neuronal survival. In various neurodegenerative disorders, the over-activation of microglia is considered to be a key causative factor in the process or, at a minimum, to promote the neuropathology. For example, in Alzheimer's disease, microglia activated by amyloid- $\beta(A \beta)$ protein, the hallmark of the disease, release neurotoxins and potentiate neuronal damage, and this microglial over-activation is an early event that precedes neuropil destruction [26]. The activated microglia cluster around or penetrate the neuritic plaques [27], supporting a critical role of microglial activation in the pathogenesis and progression of the disease. In Parkinson's disease (PD), an increased number of activated microglia are present in the vicinity of degenerating neurons [28] in the substantia nigra [29], which is particularly deleterious to dopaminergic neurons due to their glutathione deficiency [30]. A single injection of lipopolysaccharide (LPS) to activate microglia in the substantia nigra region led to a progressive, preferential and irreversible loss of dopaminergic neurons [31-33], even though LPS itself did no direct harm to the neurons, indicating that the over-activation of microglia is capable of inducing neuronal death in the absence of other pathological stimulation. All of the evidence described above supports the hypotheses of the neurotoxic features of microglia.

However, as the sentinel and essential cells of the CNS, it is unlikely that microglia would function to damage neurons in all scenarios. Once stimulated the microglia migrate rapidly to the injury site along the chemokine gradients in vitro [34] and also in response to chemoattractants including ATP and NO released directly or indirectly by the injury [35] to exert effect on the survival of neurons. In fact, some specifically designed experiments have begun to uncover the neuroprotective roles of microglia, and more studies are emerging to show beneficial functions of microglia. Firstly, studies have demonstrated instructive roles for microglia in the developing brain for neuronal differentiation [36,37] and in the regulation of neuronal apoptosis [38] through the production of neurotrophins [39]. Secondly, in the adult brain, resting microglia, which are characterized by many fine perpendicular processes extending from a few long prolongations, have been regarded as sensor cells for the detection of abnormalities or changes in the brain [40] and help to maintain environmental homeostasis. Lastly but most importantly, activated microglia have also been shown to perform neurotrophic functions following neuronal injury. One compelling study supporting this finding involves the axotomy of peripheral nerves (facial or optic), where a rapid microglial response is exhibited with the efficient clearance 
of myelin debris that contained inhibitory molecules of axon growth, finally leading to successful axonal regeneration [41]; the inhibition of this microglial response to facial nerve axotomy impairs neuronal survival [42]. In addition, in neonatal mice administered MPTP, highly activated microglia show neurotrophic potential towards dopamine neurons [43] and after traumatic injury, clear glutamate without evoking inflammatory mediators [44]. The benefits of microglial activation are further demonstrated by the exacerbation of neuropathology in inducible mouse models that are deficient in microglia [45,46], the finding of protective microglia in cases of cerebral ischemia [47] and multiple sclerosis [48] and the fact that transplantation of microglia can help to enhance neurite growth and functional recovery after CNS injury $[49,50]$. The bunch of factors that can activate microglia and the differential behavior of microglia in various conditions have been listed in Table $1 \& 2$. The above studies clearly demonstrate that microglia can be neurotrophic in the proper situations; there might be a third possibility that microglia are activated by simply reacting to pathogenic stimulation and takes very limited roles in the neurological disorders, in such case the activation of microglia is solely a result of pathogenic stimulation and work as a bystander that either involved passively during the whole process or even go to apoptosis by some other signals. Thus These activated microglia might have different phenotypes. However, the details of what conditions induce microglia to take beneficial phenotypes remain unknown. Many factors are likely involved in determining the eventual outcome of the manifestation of microglia, including their interaction with neurons or astrocytes in the same environment, age-related dysfunction of microglia, activation timing, and the activation state of the microglia, which we will be discussing below.

\section{Crosstalk between microglia and other brain cells}

Microglia have been considered to be the first line of defense in the CNS [91], a hypothesis that has been supported by the finding that microglia actively screen their microenvironment with highly motile processes; thus, the brain is under continual surveillance by microglia. To do this with high efficiency, microglia must be variable, adaptive to their environment and capable of integrating various inputs and responding appropriately [92,93]. All of these processes require significant interactions with other components within the same environment, including neurons and astrocytes.

\section{Crosstalk between microglia and neurons: neurons as regulators of microglial activation}

When we talk about whether microglia are neuroprotective or neurotoxic, we only refer to the influence of microglia on neurons. However, many studies indicate that neurons are
Table 1 Factors that can activate microglia

\begin{tabular}{|c|c|}
\hline $\begin{array}{l}\text { Substance that can } \\
\text { activate microglia }\end{array}$ & Reference \\
\hline \multicolumn{2}{|l|}{ Pathological conditions } \\
\hline hypoxia & Morigiwa et al., 2000 [51] \\
\hline tumor & Bosco et al., 2011[52] \\
\hline Ischemic insult & Hur et al., 2010 [53] \\
\hline Nerve injury & Maeda et al., 2010 [54] \\
\hline \multicolumn{2}{|l|}{ Proteins } \\
\hline a-synuclein & $\begin{array}{l}\text { Lee et al., 2010; Su et al., 2008; } \\
\text { Zhang et al., } 2005 \text { [55-57] }\end{array}$ \\
\hline amyloid-beta & Jana et al., 2008 [58] \\
\hline fibrinogen & Piers et al., 2011 [59] \\
\hline Thrombin & Lee et al., 2005 [60] \\
\hline$\underline{\text { Tissue plasminogen activator }}$ & Siao et al., 2002 [61] \\
\hline $\begin{array}{l}\text { Matrix protein } \\
\text { (vitronectin, fibronectin, MMP-3) }\end{array}$ & $\begin{array}{l}\text { Milner et al., 2007; } \\
\text { del Zoppo et al., 2007; } \\
\text { Kim et al., } 2005 \text { [62-64] }\end{array}$ \\
\hline \multicolumn{2}{|l|}{ Chemicals } \\
\hline Adenosine Triphosphate & Matsui et al., 2011 [65] \\
\hline $\begin{array}{l}\text { Toxins (MPTP, } \\
\text { Rotenone, Paraquat) }\end{array}$ & $\begin{array}{l}\text { Yasuda et al., 2008; } \\
\text { Gao et al., 2002; } \\
\text { Wu et al., 2005 } 66-68]\end{array}$ \\
\hline Alchohol & McClain et al., 2011 [69] \\
\hline Dopamine quinone & Kuhn et al., 2006 [70] \\
\hline Berberine & Lu et al., 2010 [71] \\
\hline lipopolysacchride & $\begin{array}{l}\text { Jung et al., 2010; } \\
\text { Meng et al., 2008; } \\
\text { Xu et al., } 2009 \text { [72-74] }\end{array}$ \\
\hline \multicolumn{2}{|l|}{ Cytokines } \\
\hline TNF-a & Iribarren et al., 2005 [75] \\
\hline IL-6 & Krady et al., 2008 [76] \\
\hline$\underline{\mathrm{IL}-12}$ & Tamakawa et al., 2004 [77] \\
\hline IL-3 & Natarajan et al., 2004 [78] \\
\hline $\mathrm{IFN}-\mathrm{Y}$ & $\begin{array}{l}\text { Rozenfeld et al., 2005; } \\
\text { Hall et al., } 1999 \text { [79,80] }\end{array}$ \\
\hline \multicolumn{2}{|l|}{ Others } \\
\hline gangliosides & $\begin{array}{l}\text { Kim et al., 2009; } \\
\text { Min et al., } 2004[81,82]\end{array}$ \\
\hline Kalic acid & $\begin{array}{l}\text { Zheng et al., 2010; } \\
\text { Zhu et al., } 2010[83,84]\end{array}$ \\
\hline
\end{tabular}

not merely passive targets of microglia but rather exert control over microglial activities [94]. There are considerable interactions between neurons and microglia. For example, Polazzi hypothesized that activation of microglia as a consequence of neuronal injury is primarily aimed at neuroprotection, with the loss of specific communications between neurons and microglia leading to the neurotoxic behavior of microglia [95]. Accumulating evidence demonstrates that there is significant information exchange between neurons and microglia. Depending on whether they are healthy or injured, neurons send "on" or "off" signals to influence microglial activation. On one hand, the activation of 
Table 2 Behavior of microglia in different conditions

\begin{tabular}{ll}
\hline Conditions & Microglia function \\
\hline $\begin{array}{l}\text { In steady state } \\
\text { state }\end{array}$ & $\begin{array}{l}\text { Surveillance, homeostasis [85] Fixed cell and } \\
\text { motile processes, minimal expression of cell } \\
\text { surface markers and release of cytokines } \\
\text { and chemokines, not involved in Phagocytosis }\end{array}$ \\
\hline In disease state & \\
\hline Neuroprotective & Efficient clearance of myelin debris [41] \\
\hline Axotomy of the & $\begin{array}{l}\text { Clear glutamate without evoking } \\
\text { inflammatory mediators [44] }\end{array}$ \\
\hline Traumatic injury & $\begin{array}{l}\text { Synthesis of tumor necrosis factor, } \\
\text { engulfment of harmful invading neutrophil } \\
\text { granulocytes [86] }\end{array}$ \\
\hline Ischemia & Internalize and degrade amyloid beta [87] \\
\hline Alzheimer's Disease & $\begin{array}{l}\text { Secrete soluble mediators that trigger } \\
\text { neural repair and usually contribute to the } \\
\text { creation of an environment conductive for } \\
\text { regeneration [48] }\end{array}$ \\
\hline Multiple sclerosis & \\
\hline Alzheimer's disease & $\begin{array}{l}\text { Produce of chemokines, neurotoxic } \\
\text { cytokines and reactive oxygen an dnitrogen } \\
\text { species that are deletrious to the CNS [90] }\end{array}$ \\
\hline Parkinson's disease & $\begin{array}{l}\text { Express iNOS [89] and generate toxic ROS } \\
\text { reactive oxygen species [88] }\end{array}$ \\
\hline Multiple sclerosis & \\
\hline
\end{tabular}

microglia by neuronal injury or degeneration has been widely reported $[91,96]$. On the other hand, in the healthy brain, microglial activation is tightly restricted by signaling from neurons. CD200-CD200R has been identified as one of the critical pathways in attenuating microglial activation. CD200 is a member of the immunoglobulin superfamily and is expressed on the neuronal membrane surface, while the CD200 receptor (CD200R) is primarily present in the macrophage lineage, which includes microglia [97]. The disruption of CD200-CD200R interactions results in an accelerated microglial response, whereas intensified CD200-CD200R interactions contribute to an attenuation in neurodegeneration [98]. In mice that have had CD200 selectively removed from neurons, microglia exhibited an activated phenotype and were numerous upon facial nerve transaction; damaged CD200-deficient neurons elicited an accelerated microglial response, which demonstrated a loss of the neuronal inhibitory signal for microglial response [97]. Apart from direct interactions through receptor-ligand combinations, electrical activity and soluble factors released from intact neurons also maintain microglial quiescence. In a neuron-glia co-culture, the blockade of neuronal electrical activity by tetrodotoxin or a glutamate receptor antagonist facilitated microglial activation induced by IFN- $\gamma$ [99]. Soluble molecules from neurons such as neurotrophins and anti-inflammatory agents downregulate antigen expression on cultured rat microglia $[99,100]$. Additionally, released factors from neurons can also influence the survival of microglia. Fukui et al. demonstrated that treatment with conditioned media from mature neurons significantly induced the death of microglial cells independent of LPS, while heated neuron-conditioned media or low-calcium-ion media prevented the death of microglia [101], indicating that specific factors released from neurons exert detrimental effects on microglia. It has been demonstrated that microglial cells undergo apoptosis following peripheral nerve injury [102-104] or in cases of experimental autoimmune encephalomyelitis(EAE) [105]Injured neurons induced either neuroprotective or neurotoxic behaviors in microglia depending on the manner of injury [91,106-109], providing strong evidence to support the hypothesis of crosstalk between neurons and microglia. Thus, microglia are not merely surveyors of brain tissue but also receive and actively respond to signals from neurons.

\section{Crosstalk between astrocytes and microglia: reciprocal influences}

Although less obvious than the crosstalk with neurons, the interactions between microglia and astrocytes are far from simple and are also crucial for our understanding of how microglia respond to their environment and exert influence on neuronal degeneration or regeneration. Several studies have demonstrated the substantial influence of astrocytes on microglial activation [110]. The induction of microglia by Trimethyltin or Borna disease virus-infected neurons is dependent on the presence of astrocytes $[111,112]$. Astrocytes play neuroprotective roles by modulating microglial cell activity and decreasing their cytotoxicity $[113,114]$. The expression of IL-12 and the production of inducible nitric oxide synthase (iNOS) in activated microglia have been reported to be suppressed by astrocytes or conditioned media from astrocytes [82,111,115-117], delineating the signals from astrocytes that affect the activities of microglia. Furthermore, the communication between these two types of cells is two-way; microglia both receive and give signals, as proinflammatory cytokines released from microglia inhibit gap junctions and down-regulate connexin 43 expression in astrocytes [118-120], which enhances astrocyte survival. In another study, comparative proteome analysis was performed on astrocytes that were treated with conditioned media from quiescent or activated microglia. Following culture in activated-microglial media, the anti-oxidative enzymes expressed in astrocytes were up-regulated, and these astrocytes were protected against oxidative stress. This result gave insight into the complex intercellular events that take place during neurological disorders [121]. 
As in many pathological conditions in the central nervous system such as in neurodegeneration [122], microglia, activated earlier than astrocytes, promote astrocytic activation through IL-1which is mostly from microglia [123]. On the other hand, activated astrocytes not only facilitate activation of distant microglia via calcium wave $[124,125]$, but also inhibit microglial activities [126]. Additionally, it was observed that activated-microglial-conditioned media increased astroglial proliferation [127], down-regulated the astroglial metabotropic glutamate receptor [128] and induced astroglial brain-derived neurotrophic factor (BDNF) and IL-6 gene expression [129]. Taken together, the importance of microglial activities lies in that they not only exert direct effects on neuronal survival, but they also affect the responses of other supporting cells in the same environment.

\section{Microglia-T cell crosstalk: key determinants for the trend of immune response}

The entire immune response consists of the cooperation of the innate and adaptive immune systems. In the brain, it has been postulated that the beneficial or destructive outcome of the local microglial (innate) response is determined by a well-controlled dialogue between the innate and the adaptive immune players, which are, in most cases, the microglia and T cells. Activated T cells can cross the bloodbrain barrier and interact with resident microglia in the parenchyma [130]; these microglia have been characterized as myeloid progenitor cells that can differentiate into macrophage-like or dendritic-like cells [131] and thus work crucially as the principal APCs [85] in the CNS. Monsonego et al. demonstrated that IFN- $\gamma$-treated microglia serve as efficient $A \beta$ antigen-presenting cells (APCs) of both $A \beta 1-40$ and $A \beta 1-42$, mediating CD86-dependent proliferation of $\mathrm{A} \beta$-reactive $\mathrm{T}$ cells [132]. The activated $\mathrm{T}$ cells then exert effects in the injured neural tissues by altering the reactive microglial phenotypes and inducing the astrocytic expression of growth factors or modulating microglia to act as glutamate scavengers [44] to improve neuronal survival $[133,134]$. In a model for optic nerve injury, the passive transfer of regulatory CD4 + CD25+ T cells was either destructive or beneficial depending on the genetic background of the mice tested, which determines the differential interaction of $\mathrm{T}$ cells with microglia and thus the different $\mathrm{T}$ cellmediated microglial phenotypes [133]. Kipnis even observed that both the suppressor and the effector activities of T cells could be mediated through dialogue with microglia in the condition of neurodegneration [135], The entire scenario of crosstalk between $\mathrm{T}$ cells and microglia could be described as the following: microglia are initially activated by pathological stimuli during acute or chronic injury to the brain; if the activation occurs with the proper timing and mode and is well-controlled, the activated microglia will work as APCs [133] to stimulate Treg cells that eventually modulate the microglial activation directly or indirectly and affect the milieu balance between neurotrophism and cytotoxicity $[44,136,137]$.

\section{Whether microglial activation is neurotrophic or neurotoxic is context-dependent}

After considerable time and research, we have recognized the "double-edged sword" nature of microglial cells. On one hand, significant evidence from in vitro and in vivo studies has associated neuronal injury with microglial activation [138-141]. This evidence results from an inflammatory phenotype of microglia releasing neurotoxic factors, mediators and reactive oxygen species [138-141]. On the other hand, several other studies have highlighted the beneficial and important roles of microglia in neuronal regeneration, repair and neurogenesis [142-146]. These seemingly paradoxical results cannot be directly compared, because they come from different experimental sets that vary in terms of the stimulus, timing of microglial activation and age of animals. Thus, whether microglia have positive or negative effects on neuronal survival is contextdependent.

\section{Aging can result in microglial dysfunction and subsequent neurotoxicity}

There are studies suggesting that senescence in microglia causes them to function abnormally and that the destructive roles of activated microglia in the aged neurodegenerative brain may result from age-associated microglia senescence, causing a failure of the aged microglia to respond correctly to stimuli $[147,148]$ and eventually promoting neurodegeneration [149] (Figure 1). The most prominent and also the initially identified feature of microglial senescence is the morphological alteration described as "dystrophy" [150]. Characteristics of "dystrophic" microglia observed in the aged brain include de-ramification (the loss of finely branched cytoplasmic processes), cytoplasmic beading/ spheroid formation, shortened and twisted cytoplasmic processes, and instances of partial or complete cytoplasmic fragmentation [150]. Such dystrophic microglia were prevalent and extensively distributed in the brain of older human subjects [150,151], whereas normally ramified microglial morphology with only rare instances of dystrophic microglia is observed in the young brain [148]. These observations provide initial evidence for the age-associated changes in microglia in the healthy elderly brain. Telomere shortening, a marker of aging, has also been demonstrated in microglia in the aged brain in Flanary's study, who reported that microglial cells in rats exhibit significant telomere shortening and a reduction in telomerase activity during normal aging [152]. More importantly, microglial senescence is also manifested by functional alterations, such as an altered inflammatory profile, increased immunophenotypic expression, and the switch from neuroprotective 


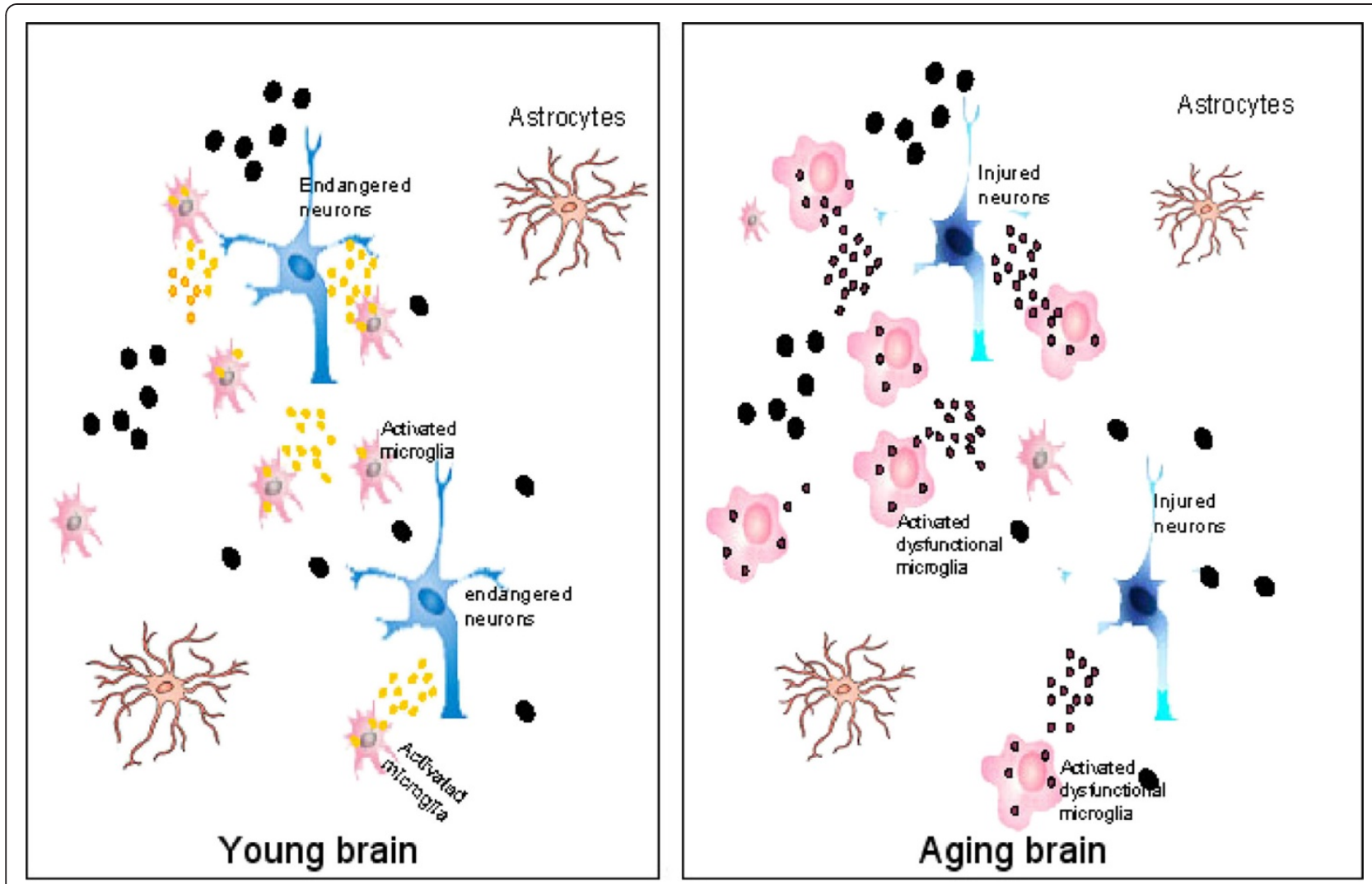

Figure 1 Age-primed microglia hypothesis of Parkinson's disease. Microglia functions differentially in the young (left) and aged (right) brain. Left: when facing pathogenic stimuli (large black dots), the healthy microglia in the young brain respond by releasing neurotrophic factors (small yellow dots) to support the endangered dopaminergic neurons and limit neuronal damages. Right: in the aged brain oxidative stress and inflammatory factors (small black dots), which damage the vulnerable dopaminergic neurons and eventually lead to neurodegeneration. (From Luo et al.,2010 with permission).

in the young brain to neurotoxic in the aged brain upon activation [147]. Also, the timing of microglial proliferation and presentation in the injured aged brain is distinct from that in the young brain. For example, Conde et al. reported that microglial proliferation rates in the aged rat brain were significantly higher than in the young rat brain four days after axotomy of the facial nerve [148]. The distinct pattern of the microglial response to injury in the aged brain has also been recorded in the 1-methyl-4-phenyl-1,2,3,6-tetrahydropyridine (MPTP)-induced model of neurotoxicity [153], the model of controlled cortical impact (CCI) [154], cortical stab injury [155] and transient retinal ischemia [156]. Although more attention has been paid to the dysfunction of aged microglia, many critical questions remain unanswered. Some of these questions are: whether the activated state of microglia in the aging brain is concurrent with or secondary to microglial dystrophy; which specific function of microglia is primarily affected by microglial dystrophy, how it is affected and what is the direct consequence of the affected function; and whether the deterioration of a specific microglial function is more related to neurodegeneration than others. Clearly, more research is needed to answer these questions.

\section{The timing of activation is an indispensible determinant of microglial function}

Another important element that critically determines the destructive or neuroprotective role of microglia is the timing of their activation. Because large and very complicated communications pathways exist between immunocompetent cells and cytokines in the CNS, the timing of microglial activation leads to diverse trends and outcomes related to the entire inflammation event. In a model of optic nerve crush injury, Shaked et al. found that an earlier onset of phagocytic activity and antigen presentation by microglia results in a resistance to injury and neurons survived [133]; the early, moderate, transient and well-controlled activation of local microglia caused them to function as APCs, leading to the communication with Treg cells that subsequently proves to be neuroprotective through the modulation of microglial activation states [133]. In a multiple sclerosis (MS) 
model of experimental allergic encephalomyelitis (EAE) [157], the inhibition of microglial activation through tPA knockout (tissue plasminogen activator, an essential element for microglia activation) leads to a delayed onset of the disease but increased severity and delayed recovery from the neurological dysfunction, which suggests that microglial activation is harmful during the onset of the disease but beneficial in the recovery phase [157]. Furthermore, when microglial activation was either stimulated or inhibited at different stages, the disease progression was attenuated or exacerbated accordingly [158]. For example, the inhibition of microglial activation at EAE onset, rather than prior to EAE induction, markedly decreased EAE progression, while the stimulation of microglial activation prior to the onset of EAE promotes lower-level EAE and an earlier recovery from symptoms. Together, these findings suggest different roles for microglial activation during various phases of the disease and that different timing of microglial activation dramatically affects whether microglia will be neuroprotective or deleterious [158]. Similarly, in an oxygen-glucose deprivation model, the time window of microglial neuroprotection has been estimated to up to 48 hour after injury, while the pre-stimulation of microglia with LPS before the injury fails to induce microglial-mediated neuroprotection [86]. It has been proposed that the effects of the early activation of microglia on disease progression could be beneficial through phagocytic activity and antigen presentation, recruitment and interactions with the adaptive immune response and the induction of protective autoimmunity [133]. Furthermore, the balance between protective autoimmunity and autoimmune disease may be determined by the timing and intensity of microglial activation [133]. As the immuno-competent cells in the CNS, microglia are critical determinants of the outcome of injury, and the timing of microglial activation appears to be crucial to the outcome of the injury. Thus, any interference with microglial activation in an attempt to affect the disease course clearly must be temporally-restricted.

\section{Activation states of microglia}

Two distinct phenotypes of macrophages have long been known to play different roles in the inflammatory context. Classically-activated macrophages, characterized by the involvement of $\mathrm{T}$ Helper type 1 (Th-1) cytokines such as interferon- $\gamma$, promote the release of various proinflammatory cytokines and thus exacerbate the inflammation. Alternatively, activated macrophages predominate in the T Helper type 2 (Th-2) microenvironment and tend to soothe the inflammation. Thus, the behavior of macrophages is dictated by their phenotype, which may eventually affect the beneficial or detrimental roles of macrophages during inflammation. Similarly, research over the past few years has established that microglia do not constitute a single, uniform cell population, but rather comprise a family of cells with diverse phenotypes; some are neuroprotective while others are destructive [92]. So far, three distinct functions have been proposed for microglia. The first is the classical activation state of microglia, which, accompanied by the induction of receptors that participate in the innate immune response [159], is responsible for the pro-inflammatory milieu, and has been linked to neurotoxic effects in the brain. The second is alternatively activated microglia, which are associated with the production of anti-inflammatory cytokines in the resolution phase of the inflammatory response. Recently, the third activation state of microglia has been identified: it overlaps with and is complementary to the alternative activation and is called acquired deactivation $[160,161]$. This is another activation state that promotes immunosuppression and is associated with the anti-inflammatory and functional repair phenotype .Both alternative activation and acquired deactivation down-regulate innate immune responses and have similar gene profiles; the most prominent difference is that acquired deactivation is induced by the exposure of microglia to apoptotic cells or to TGF- $\beta$ or IL-10, while IL-4 and IL-13 induce alternative activation $[160,161]$. It has been observed that multiple activation states of microglia coexist in certain chronic inflammations due to parasitic disease [162], in which the balance between classical activation and alternative activation/acquired deactivation states is of "benefit" to both host and parasite: the host benefits from reduced self-damage, and the parasite eventually survives within the host. Neurodegenerative disorders are also associated with chronic inflammation and the coexistence of various activation states. For example, in $\mathrm{AD}$, some levels of classical activation may be required to limit the brain levels of $A \beta$ despite the risk of self-damage [163], while alternative activation of microglia in AD may foster the protection of the surrounding tissue from immune damage even though it may facilitate $A \beta$ deposits. Similar studies [164-166] have shown that the immune cells in the vicinity of amyloid deposits in AD express mRNA and proteins for pro-inflammatory cytokines, leading to the hypothesis that microglia demonstrate classical activation in $\mathrm{AD}$, while Colton et al. found increased mRNA expression of alternative activation-associated gene profiles in microglia in both the AD brain and an AD mouse model [167], suggesting the presence of multiple activation states of microglia during neurodegeneration. However, the recognition of heterogeneous phenotypes of microglia only raises more questions: what instructs microglia to acquire a particular phenotype; can any conversion occur between these phenotypes; and is it possible to avoid or at least change the commitment to a destructive phenotype? All of these questions are difficult to answer with our current knowledge of 
microglia; more extensive work is warranted before we can reach a conclusion.

\section{The stimulus type is another turning point for microglial function}

As an active sensor in the brain, microglia respond to even minor stimuli; however, different types of stimulation may also lead to different actions of microglia and thus be either harmful or beneficial to neuronal survival. In a neonatal mouse MPTP-induced brain injury model, microglia activated by systemic administration of LPS were shown to be neuroprotective. In contrast to the MPTP model, LPS-activated microglia in neonatal mice receiving a stereotaxic injection of ethanol into the striatum were shown to be neurotoxic, and systemic LPS administration in the ethanol-injury model caused a marked increase both in the volume of necrotic lesions and in the number of degenerating neurons in the striatum [168]. Even with the same stimuli, the degree can also determine microglial release of toxic versus protective effectors [169]; neurotoxic cytokines and ROS were released from microglia only in response to mild neuronal injuries, while trophic microglial effectors such as BDNF and GDNF were up-regulated in response to all degrees of neuronal injury [169]. Additionally, different types of pain resulted in differing activations of microglia [170].

So far, what we know is that not all microglia respond in the same way, even to the same stimulus, and microglial function is tailored in a context-specific manner [171]. Numerous elements are involved in this context; most likely there are many more beyond what we have discussed here. Identifying these elements and clarifying their interactions or crosstalk with microglia is essential before we are able to design a strategy to control inflammation through the manipulation of microglia. The simple therapy of inhibiting all microglia without differentiating their function in a context-dependent manner surely should be abandoned.

\section{Microglia and neurogenesis}

It has been long recognized that the birth of new neurons within the postnatal brain continues throughout life and remains as a potential source of replacement cells in the $\mathrm{CNS}$ for the treatment of disease. The microenvironment or the niche in which neural progenitor cells live critically influences the process of neurogenesis, which spans several steps including the proliferation of stem or progenitor cells; the survival of immature or mature neurons; the migration of new neuroblasts to their appropriate locations; and the differentiation of neuroblasts to a neuronal phenotype and the construction of synaptic connectivity [172]. As an important component of the brain microenvironment and due to their invariant participation in most pathological processes in the CNS, microglia are increasingly implicated as a potential non-neural regulator of neurogenesis, as demonstrated by circumstantial evidence [144,172]. However, just as in the debate over the neuroprotective or neurotoxic nature of microglial activation, whether microglia support or damage the survival and development of neural progenitor cells also remains controversial. On one hand, microglia were shown to play instructive roles during postnatal neurogenesis in the neurogenic niche either by influencing the differentiation of stem cells toward a neuronal phenotype or by directing their migration [144,173-175]. On the other hand, multiple studies have demonstrated the deleterious effect of microglial activation on neurogenesis $[176,177]$ and the effective restoration of neurogenesis though the blockade of microglial activation.

In the two situations of neurogenesis and neuronal survival, similar factors are shared, leading microglia to take supportive or detrimental roles. Among these factors, the most prominent is the microglial activation phenotype that is associated with different cytokine profiles. When acutely activated by either LPS or injury, microglia that release the pro-inflammatory cytokines IL- 6 , TNF- $\alpha$ or IL- $1 \beta$ usually down-regulate the differentiation or proliferation of neural stem cells or induce the aberrant migration of newborn neurons [178]. This group of inflammatory cytokines has been proven to inhibit neurogenesis [176,177,179]; conversely, blocking antibodies to these pro-inflammatory cytokines (such as IL-6 [177]) or the use of monocycline to mitigate the microglial activation simply restores neurogenesis [176]. In contrast, microglia that are activated by anti-inflammatory cytokines such as IL- 4 or TGF- $\beta$ increase neurogenesis in vitro or the differentiation of neural stem cells (NSCs) in vivo [180,181]. Neurotrophins, such as IGF-1, were identified [181] in anti-inflammatory cytokineactivated microglia and were proposed to be one of the mechanisms underlying this pro-neurogenic activity of microglia [182,183]. However, just like the dual roles in neuroprotection, whether a specific cytokine-activated microglial cell will take a pro- or anti-neurogenic role is also context-dependent. For example, microglial cells activated by IFN- $\gamma$, a pro-inflammatory cytokine can be neurotoxic or supportive of neurogenesis, depending on the concentration of IFN- $\gamma$ [184]. TGF- $\beta$, which is considered to be beneficial to neurogenesis, can actually exert a negative influence on neurogenesis when it is chronically produced in the aged brain [185]. Additionally, if other cytokines exist in the same niche simultaneously, the outcome will be determined by the balance among the various cytokines; some authors have concluded that activated microglia are not pro- or anti-neurogenic per se, but the balance between pro- and anti-inflammatory secreted molecules influences the final effect of microglial activation $[172,180]$. However, in which situations the microglia will release pro- or anti-inflammatory cytokines is complicated and is affected by multiple factors such as the injury 
type, the phase of disease or inflammation, and crosstalk with other regulating components, including neural precursors; this is similar to the question of whether microglia will be neuroprotective or neurotoxic. Most likely the same inflammatory scenario that induces neurodegeneration would also inhibit neurogenesis, while a situation that favors neuronal survival would also support neurogenesis. Interestingly, even in a high-inflammation environment, such as two days after a Trimethyltin-induced acute injury in the hippocampus, significant neurogenesis can be detected [186,187], suggesting a complicated system of neurogenesis regulation beyond the inflammation scenario.

Cumulative studies have found an age-related decline in neurogenesis, both in the aged adult and in the diseased brain. Because aging may contribute to microglial dysfunction and neurotoxicity, as we discussed previously in this review, one could assume that microglial dysfunction may also be involved in the downregulation of neurogenesis in the aged or diseased brain $[188,189]$. Even though very few studies have focused on the effect of microglial dysfunction on neurogenesis, we can still find a clue from Zhu's study that the difference in microglia function patterns between the immature and juvenile brain might be related to a decrease in neurogenesis in the juvenile brain [190]; however, stronger evidence from the direct comparison of microglia-associated neurogenesis between aged and young brains is needed to support this view.

Another important element regulating the activities of microglia is the $\mathrm{T}$ cell, which comes from the peripheral adaptive immune system and enters the CNS by extravasating across the endothelium of the choroid plexus into the cerebrospinal fluid [191]. The interaction of $\mathrm{T}$ cells with microglia in the injured spinal cord correlates with enhanced neuronal survival [184], and rapidly recruited T cells in the middle cerebral artery obstruction (MCAO) model increased hippocampal and cortical neurogenesis by modulating the microglial response and through the production of IGF in the sub-acute phase [192]. Hippocampal neurogenesis was associated with the recruitment of $\mathrm{T}$ cells and microglial activation. Immune-deficient mice show impaired neurogenesis in the hippocampus, but this deficiency was attenuated and neurogenesis boosted by $\mathrm{T}$ cells recognizing a specific CNS antigen [193]. The cellular source of IFN- $\gamma$ and IL-4 in vivo is likely to be T cells, therefore it is reasonable to assume that the T cell-mediated immune response is an integral part of the regulation of microglial phenotype or function, and thus can influence neuronal survival or neurogenesis directly or indirectly.

\section{Conclusion}

From an increasing number of studies of diverse microglial activity in different experimental sets, we are beginning to appreciate the heterogeneity of microglial functions that have either beneficial or detrimental roles in specific physiological or pathological environments. Whether microglia are committed to one function from the very beginning or if there is any conversion between different phenotypes remains elusive and the factors that initiate this commitment or promote its conversion are far from being clarified. Due to the invariant critical participation of microglia in most diseases, ongoing research to uncover these questions is warranted; before we are sure about the answer, any potential strategies targeting microglia to manipulate inflammation and modify a disease course are unrealistic.

\section{Competing interests}

The authors declare that they have no competing interests.

\section{Acknowledgement}

This work was funded by the National Program of Basic Research (2010CB945200, 2011CB504104) of China, the National Nature Science Fund (No.30973153, No.30772280), Liaoning Doctoral Starting Fund (20071042), and the Foundation of the Liaoning Educational Committee (L202013136, L2010560).

\section{Authors' contributions}

$\mathrm{XL}$ drafted the manuscript, SC critically revised the manuscript. All authors read and approved the final manuscript.

\section{Author details}

${ }^{1}$ Department of Neurology, First Affiliated Hospital of China Medical University, Shenyang 110001, China. ${ }^{2}$ Department of Neurology \& Institute of Neurology, Ruijin Hospital affiliated to Shanghai Jiao Tong University, Shanghai 200025, China.

Received: 1 January 2012 Accepted: 24 April 2012

Published: 24 April 2012

\section{References}

1. Farber K, Kettenmann H: Purinergic signaling and microglia. Pflugers Arch 2006, 452:615-621.

2. Hanisch UK, Kettenmann H: Microglia: active sensor and versatile effector cells in the normal and pathologic brain. Nat Neurosci 2007, 10:1387-1394.

3. Kettenmann H, Hanisch UK, Noda M, Verkhratsky A: Physiology of microglia. Physiol Rev 2011, 91:461-553.

4. Kettenmann H, Banati R, Walz W: Electrophysiological behavior of microglia. Glia 1993, 7:93-101.

5. Noda M, Kettenmann H, Wada K: Anti-inflammatory effects of kinins via microglia in the central nervous system. Biol Chem 2006, 387:167-171.

6. Pocock JM, Kettenmann H: Neurotransmitter receptors on microglia. Trends Neurosci 2007, 30:527-535.

7. Skoff RP: The fine structure of pulse labeled (3-H-thymidine cells) in degenerating rat optic nerve. J Comp Neurol 1975, 161:595-611.

8. Kitamura T, Miyake T, Fujita S: Genesis of resting microglia in the gray matter of mouse hippocampus. J Comp Neurol 1984, 226:421-433.

9. Alliot F, Lecain E, Grima B, Pessac B: Microglial progenitors with a high proliferative potential in the embryonic and adult mouse brain. Proc Natl Acad Sci U S A 1991, 88:1541-1545.

10. Priller J, Flugel A, Wehner T, Boentert M, Haas CA, Prinz M, Fernandez-Klett F, Prass $K$, Bechmann I, de Boer BA, et al: Targeting gene-modified hematopoietic cells to the central nervous system: use of green fluorescent protein uncovers microglial engraftment. Nat Med 2001, 7:1356-1361.

11. Ritter MR, Banin E, Moreno SK, Aguilar E, Dorrell MI, Friedlander M: Myeloid progenitors differentiate into microglia and promote vascular repair in a model of ischemic retinopathy. J Clin Invest 2006, 116:3266-3276.

12. Ling EA, Penney D, Leblond CP: Use of carbon labeling to demonstrate the role of blood monocytes as precursors of the 'ameboid cells' present in the corpus callosum of postnatal rats. J Comp Neurol 1980, 193:631-657. 
13. Davoust N, Vuaillat C, Cavillon G, Domenget C, Hatterer E, Bernard A, Dumontel C, Jurdic P, Malcus C, Confavreux C, et al: Bone marrow CD34+/B220+ progenitors target the inflamed brain and display in vitro differentiation potential toward microglia. Faseb J 2006, 20:2081-2092.

14. Schmitz G, Leuthauser-Jaschinski K, Orso E: Are circulating monocytes as microglia orthologues appropriate biomarker targets for neuronal diseases? Cent Nerv Syst Agents Med Chem 2009, 9:307-330.

15. Djukic M, Mildner A, Schmidt H, Czesnik D, Bruck W, Priller J, Nau R, Prinz M: Circulating monocytes engraft in the brain, differentiate into microglia and contribute to the pathology following meningitis in mice. Brain 2006, 129:2394-2403.

16. Templeton SP, Kim TS, O'Malley K, Perlman S: Maturation and localization of macrophages and microglia during infection with a neurotropic murine coronavirus. Brain Pathol 2008, 18:40-51.

17. Liu M, Equchi N, Yamasaki Y, Urade Y, Hattori N, Urabe T: Focal cerebral ischemia/reperfusion injury in mice induces hematopoietic prostaglandin D synthase in microglia and macrophages. Neuroscience 2007, 145:520-529.

18. Luo X, Carlson KA, Wojna V, Mayo R, Biskup TM, Stoner J, Anderson J, Gendelman HE, Melendez LM: Macrophage proteomic fingerprinting predicts HIV-1-associated cognitive impairment. Neurology 2003, 60:1931-1937.

19. Balasubramaniam B, Carter DA, Mayer EJ, Dick AD: Microglia derived IL-6 suppresses neurosphere generation from adult human retinal cell suspensions. Exp Eye Res 2009, 89:757-766.

20. Dheen ST, Jun Y, Yan Z, Tay SS, Ling EA: Retinoic acid inhibits expression of TNF-alpha and iNOS in activated rat microglia. Glia 2005, 50:21-31.

21. Bi XL, Yang JY, Dong YX, Wang JM, Cui YH, Ikeshima T, Zhao YQ, Wu CF: Resveratrol inhibits nitric oxide and TNF-alpha production by lipopolysaccharide-activated microglia. Int Immunopharmacol 2005 5:185-193.

22. Moss DW, Bates TE: Activation of murine microglial cell lines by lipopolysaccharide and interferon-gamma causes NO-mediated decreases in mitochondrial and cellular function. Eur J Neurosci 2001, 13:529-538.

23. Liu B, Gao HM, Wang JY, Jeohn GH, Cooper CL, Hong JS: Role of nitric oxide in inflammation-mediated neurodegeneration. Ann N Y Acad Sci 2002, 962:318-331.

24. Colton CA, Gilbert DL: Production of superoxide anions by a CNS macrophage, the microglia. FEBS Lett 1987, 223:284-288.

25. Mao H, Liu B: Synergistic microglial reactive oxygen species generation induced by pesticides lindane and dieldrin. Neuroreport 2008, 19:1317-1320.

26. Cagnin A, Brooks DJ, Kennedy AM, Gunn RN, Myers R, Turkheimer FE, Jones T, Banati RB: In-vivo measurement of activated microglia in dementia. Lancet 2001, 358:461-467.

27. McGeer PL, Itagaki S, Tago H, McGeer EG: Reactive microglia in patients with senile dementia of the Alzheimer type are positive for the histocompatibility glycoprotein HLA-DR. Neurosci Lett 1987, 79:195-200.

28. Imamura K, Hishikawa N, Sawada M, Nagatsu T, Yoshida M, Hashizume Y: Distribution of major histocompatibility complex class II-positive microglia and cytokine profile of Parkinson's disease brains. Acta Neuropathol 2003, 106:518-526.

29. Lawson $\sqcup$, Perry VH, Dri P, Gordon S: Heterogeneity in the distribution and morphology of microglia in the normal adult mouse brain. Neuroscience 1990, 39:151-170.

30. Loeffler DA, DeMaggio AJ, Juneau PL, Havaich MK, LeWitt PA: Effects of enhanced striatal dopamine turnover in vivo on glutathione oxidation. Clin Neuropharmacol 1994, 17:370-379.

31. Castano A, Herrera AJ, Cano J, Machado A: Lipopolysaccharide intranigral injection induces inflammatory reaction and damage in nigrostriatal dopaminergic system. J Neurochem 1998, 70:1584-1592.

32. Liu B, Jiang JW, Wilson BC, Du L, Yang SN, Wang JY, Wu GC, Cao XD, Hong $J S$ : Systemic infusion of naloxone reduces degeneration of rat substantia nigral dopaminergic neurons induced by intranigral injection of lipopolysaccharide. J Pharmacol Exp Ther 2000, 295:125-132.

33. Lu X, Bing G, Hagg T: Naloxone prevents microglia-induced degeneration of dopaminergic substantia nigra neurons in adult rats. Neuroscience 2000, 97:285-291.

34. Cartier L, Hartley O, Dubois-Dauphin M, Krause KH: Chemokine receptors in the central nervous system: role in brain inflammation and neurodegenerative diseases. Brain Res Brain Res Rev 2005, 48:16-42.

35. Duan $Y$, Sahley CL, Muller KJ: ATP and NO dually control migration of microglia to nerve lesions. Dev Neurobiol 2009, 69:60-72.
36. Farinas I, Cano-Jaimez M, Bellmunt E, Soriano M: Regulation of neurogenesis by neurotrophins in developing spinal sensory ganglia. Brain Res Bull 2002, 57:809-816.

37. Markus A, Patel TD, Snider WD: Neurotrophic factors and axonal growth. Curr Opin Neurobiol 2002, 12:523-531.

38. Oppenheim RW, Prevette D, Tytell M, Homma S: Naturally occurring and induced neuronal death in the chick embryo in vivo requires protein and RNA synthesis: evidence for the role of cell death genes. Dev Biol 1990, 138:104-113.

39. Miller FD, Kaplan DR: Neurotrophin signalling pathways regulating neuronal apoptosis. Cell Mol Life Sci 2001, 58:1045-1053.

40. Nimmerjahn A, Kirchhoff F, Helmchen F: Resting microglial cells are highly dynamic surveillants of brain parenchyma in vivo. Science 2005, 308:1314-1318.

41. Battisti WP, Wang J, Bozek K, Murray M: Macrophages, microglia, and astrocytes are rapidly activated after crush injury of the goldfish optic nerve: a light and electron microscopic analysis. J Comp Neurol 1995, 354:306-320.

42. Hao HP, Doh-Ura K, Nakanishi H: Impairment of microglial responses to facial nerve axotomy in cathepsin S-deficient mice. J Neurosci Res 2007, $85: 2196-2206$

43. Sawada H, Hishida R, Hirata Y, Ono K, Suzuki H, Muramatsu S, Nakano I, Nagatsu T, Sawada M: Activated microglia affect the nigro-striatal dopamine neurons differently in neonatal and aged mice treated with 1-methyl-4-phenyl-1,2,3,6tetrahydropyridine. J Neurosci Res 2007, 85:1752-1761.

44. Shaked I, Tchoresh D, Gersner R, Meiri G, Mordechai S, Xiao X, Hart RP Schwartz M: Protective autoimmunity: interferon-gamma enables microglia to remove glutamate without evoking inflammatory mediators. J Neurochem 2005, 92:997-1009.

45. Bruccoleri A, Harry GJ: Chemical-induced hippocampal neurodegeneration and elevations in TNFalpha, TNFbeta, IL-1alpha, IP-10, and MCP-1 mRNA in osteopetrotic (op/op) mice. J Neurosci Res 2000, 62:146-155.

46. Lalancette-Hebert M, Gowing G, Simard A, Weng YC, Kriz J: Selective ablation of proliferating microglial cells exacerbates ischemic injury in the brain. J Neurosci 2007, 27:2596-2605.

47. Lambertsen KL, Clausen BH, Babcock AA, Gregersen R, Fenger C, Nielsen HH, Haugaard LS, Wirenfeldt M, Nielsen M, Dagnaes-Hansen F, et al: Microglia protect neurons against ischemia by synthesis of tumor necrosis factor. J Neurosci 2009, 29:1319-1330

48. Napoli I, Neumann H: Protective effects of microglia in multiple sclerosis. Exp Neurol 2010, 225:24-28.

49. Rapalino O, Lazarov-Spiegler O, Agranov E, Velan GJ, Yoles E, Fraidakis M Solomon A, Gepstein R, Katz A, Belkin M, et al: Implantation of stimulated homologous macrophages results in partial recovery of paraplegic rats. Nat Med 1998, 4:814-821.

50. Rabchevsky AG, Streit WJ: Grafting of cultured microglial cells into the lesioned spinal cord of adult rats enhances neurite outgrowth. J Neurosci Res 1997, 47:34-48.

51. Morigiwa K, Quan M, Murakami M, Yamashita M, Fukuda Y: P2 Purinoceptor expression and functional changes of hypoxia-activated cultured rat retinal microglia. Neurosci Lett 2000, 282:153-156.

52. Bosco A, Steele MR, Vetter ML: Early microglia activation in a mouse model of chronic glaucoma. J Comp Neurol 2011, 519:599-620.

53. Hur J, Lee P, Kim MJ, Kim Y, Cho YW: Ischemia-activated microglia induces neuronal injury via activation of gp91phox NADPH oxidase. Biochem Biophys Res Commun 2010, 391:1526-1530.

54. Maeda M, Tsuda M, Tozaki-Saitoh H, Inoue K, Kiyama H: Nerve injuryactivated microglia engulf myelinated axons in a P2Y12 signalingdependent manner in the dorsal horn. Glia 2010, 58:1838-1846.

55. Lee EJ, Woo MS, Moon PG, Baek MC, Choi IY, Kim WK, Junn E, Kim HS: Alpha-synuclein activates microglia by inducing the expressions of matrix metalloproteinases and the subsequent activation of proteaseactivated receptor-1. J Immunol 2010, 185:615-623.

56. Su X, Maguire-Zeiss KA, Giuliano R, Prifti L, Venkatesh K, Federoff HJ: Synuclein activates microglia in a model of Parkinson's disease. Neurobiol Aging 2008, 29:1690-1701.

57. Zhang W, Wang T, Pei Z, Miller DS, Wu X, Block ML, Wilson B, Zhang W, Zhou Y, Hong JS, Zhang J: Aggregated alpha-synuclein activates microglia: a process leading to disease progression in Parkinson's disease. Faseb J 2005, 19:533-542. 
58. Jana M, Palencia CA, Pahan K: Fibrillar amyloid-beta peptides activate microglia via TLR2: implications for Alzheimer's disease. J Immunol 2008, 181:7254-7262.

59. Piers TM, Heales SJ, Pocock JM: Positive allosteric modulation of metabotropic glutamate receptor 5 down-regulates fibrinogen-activated microglia providing neuronal protection. Neurosci Lett 2011, 505:140-145.

60. Lee DY, Oh YJ, Jin BK: Thrombin-activated microglia contribute to death of dopaminergic neurons in rat mesencephalic cultures: dual roles of mitogen-activated protein kinase signaling pathways. Glia 2005, 51:98-110.

61. Siao CJ, Tsirka SE: Tissue plasminogen activator mediates microglial activation via its finger domain through annexin II. J Neurosci 2002, 22:3352-3358

62. Milner R, Crocker SJ, Hung S, Wang X, Frausto RF, del Zoppo GJ: Fibronectin- and vitronectin-induced microglial activation and matrix metalloproteinase- 9 expression is mediated by integrins alpha5beta1 and alphavbeta5. J Immunol 2007, 178:8158-8167.

63. Kim YS, Kim SS, Cho JJ, Choi DH, Hwang O, Shin DH, Chun HS, Beal MF, Joh $\mathrm{TH}$ : Matrix metalloproteinase-3: a novel signaling proteinase from apoptotic neuronal cells that activates microglia. J Neurosci 2005, 25:3701-3711.

64. del Zoppo GJ, Milner R, Mabuchi T, Hung S, Wang X, Berg Gl, Koziol JA: Microglial activation and matrix protease generation during focal cerebral ischemia. Stroke 2007, 38:646-651.

65. Matsui T, Motoki Y, Inomoto T, Miura D, Kato Y, Suenaga H, Hino K, Nojima J: Temperature-Related Effects of Adenosine Triphosphate-Activated Microglia on Pro-Inflammatory Factors. Neurocrit Care 2011.

66. Yasuda Y, Shimoda T, Uno K, Tateishi N, Furuya S, Yagi K, Suzuki K, Fujita S: The effects of MPTP on the activation of microglia/astrocytes and cytokine/chemokine levels in different mice strains. J Neuroimmuno/ 2008, 204:43-51.

67. Gao HM, Hong JS, Zhang W, Liu B: Distinct role for microglia in rotenoneinduced degeneration of dopaminergic neurons. J Neurosci 2002, 22:782-790.

68. Wu XF, Block ML, Zhang W, Qin L, Wilson B, Zhang WQ, Veronesi B, Hong JS: The role of microglia in paraquat-induced dopaminergic neurotoxicity. Antioxid Redox Signal 2005, 7:654-661.

69. McClain JA, Morris SA, Deeny MA, Marshall SA, Hayes DM, Kiser ZM, Nixon K: Adolescent binge alcohol exposure induces long-lasting partial activation of microglia. Brain Behav Immun 2011, 25(Suppl 1):S120-S128.

70. Kuhn DM, Francescutti-Verbeem DM, Thomas DM: Dopamine quinones activate microglia and induce a neurotoxic gene expression profile: relationship to methamphetamine-induced nerve ending damage. Ann N Y Acad Sci 2006, 1074:31-41.

71. Lu DY, Tang $\mathrm{CH}$, Chen YH, Wei $I H$ : Berberine suppresses neuroinflammatory responses through AMP-activated protein kinase activation in BV-2 microglia. J Cell Biochem 2010, 110:697-705.

72. Jung HW, Oh TW, Jung JK, Lee JH, Shin GJ, Park YK: Inhibitory Effects of the Methylene Chloride Fraction of JP05 on the Production of Inflammatory Mediators in LPS-activated BV2 Microglia. Inflammation 2010, 35:332-341.

73. Meng XL, Yang JY, Chen GL, Zhang LJ, Wang LH, Li J, Wang JM, Wu CF: RV09, a novel resveratrol analogue, inhibits NO and TNF-alpha production by LPS-activated microglia. Int Immunopharmacol 2008, 8:1074-1082.

74. Xu Y, Xue Y, Wang Y, Feng D, Lin S, Xu L: Multiple-modulation effects of Oridonin on the production of proinflammatory cytokines and neurotrophic factors in LPS-activated microglia. Int Immunopharmacol 2009, 9:360-365.

75. Iribarren $\mathrm{P}$, Chen $\mathrm{K}$, Hu J, Zhang X, Gong W, Wang JM: IL-4 inhibits the expression of mouse formyl peptide receptor 2 , a receptor for amyloid beta 1-42, in TNF-alpha-activated microglia. J Immunol 2005, 175:6100-6106.

76. Krady JK, Lin HW, Liberto CM, Basu A, Kremlev SG, Levison SW: Ciliary neurotrophic factor and interleukin- 6 differentially activate microglia. $J$ Neurosci Res 2008, 86:1538-1547.

77. Tamakawa N, Saio M, Suwa T, Ohe N, Yoshimura S, Iwama T, Shinoda J, Sakai N, Takami T: Interleukin-2 activated microglia engulf tumor infiltrating T cells in the central nervous system. Int J Mol Med 2004, 13:497-503.

78. Natarajan C, Sriram S, Muthian G, Bright JJ: Signaling through JAK2-STAT5 pathway is essential for IL-3-induced activation of microglia. Glia 2004, 45:188-196.

79. Rozenfeld C, Martinez R, Seabra S, Sant'anna C, Goncalves JG, Bozza M, Moura-Neto V, De Souza W: Toxoplasma gondii prevents neuron degeneration by interferon-gamma-activated microglia in a mechanism involving inhibition of inducible nitric oxide synthase and transforming growth factor-beta1 production by infected microglia. Am J Pathol 2005, 167:1021-1031.

80. Hall GL, Girdlestone J, Compston DA, Wing MG: Recall antigen presentation by gamma-interferon-activated microglia results in $T$ cell activation and propagation of the immune response. J Neuroimmunol 1999, 98:105-111.

81. Kim KS, Park JY, Jou I, Park SM: Functional implication of BAFF synthesis and release in gangliosides-stimulated microglia. J Leukoc Biol 2009, 86:349-359.

82. Min KJ, Yang MS, Kim SU, Jou I, Joe EH: Astrocytes induce hemeoxygenase-1 expression in microglia: a feasible mechanism for preventing excessive brain inflammation. J Neurosci 2006, 26:1880-1887.

83. Zheng $H$, Zhu W, Zhao H, Wang X, Wang W, Li Z: Kainic acid-activated microglia mediate increased excitability of rat hippocampal neurons in vitro and in vivo: crucial role of interleukin-1beta. Neuroimmunomodulation 2010, 17:31-38.

84. Zhu W, Zheng H, Shao X, Wang W, Yao Q, Li Z: Excitotoxicity of TNFalpha derived from KA activated microglia on hippocampal neurons in vitro and in vivo. J Neurochem 2010, 114:386-396.

85. Aloisi F: Immune function of microglia. Glia 2001, 36:165-179.

86. Neumann J, Sauerzweig S, Ronicke R, Gunzer F, Dinkel K, Ullrich O, Gunzer M, Reymann KG: Microglia cells protect neurons by direct engulfment of invading neutrophil granulocytes: a new mechanism of CNS immune privilege. J Neurosci 2008, 28:5965-5975.

87. Lee CY, Landreth GE: The role of microglia in amyloid clearance from the AD brain. J Neural Transm 2010, 117:949-960.

88. Teismann P, Schulz JB: Cellular pathology of Parkinson's disease: astrocytes, microglia and inflammation. Cell Tissue Res 2004, 318:149-161.

89. Hill KE, Zollinger LV, Watt HE, Carlson NG, Rose JW: Inducible nitric oxide synthase in chronic active multiple sclerosis plaques: distribution, cellular expression and association with myelin damage. J Neuroimmunol 2004, 151:171-179.

90. Mandrekar-Colucci S, Landreth GE: Microglia and inflammation in Alzheimer's disease. CNS Neurol Disord Drug Targets 2010, 9:156-167.

91. Kreutzberg GW: Microglia: a sensor for pathological events in the CNS. Trends Neurosci 1996, 19:312-318.

92. Schwartz M, Butovsky O, Bruck W, Hanisch UK: Microglial phenotype: is the commitment reversible? Trends Neurosci 2006, 29:68-74.

93. Hanisch UK: Microglia as a source and target of cytokines. Glia 2002, 40:140-155

94. Biber K, Neumann H, Inoue K, Boddeke HW: Neuronal 'On' and 'Off' signals control microglia. Trends Neurosci 2007, 30:596-602.

95. Polazzi $\mathrm{E}_{1}$ Contestabile $\mathrm{A}$ : Reciprocal interactions between microglia and neurons: from survival to neuropathology. Rev Neurosci 2002, 13:221-242.

96. Zhou Y, Wang Y, Kovacs M, Jin J, Zhang J: Microglial activation induced by neurodegeneration: a proteomic analysis. Mol Cell Proteomics 2005, 4:1471-1479.

97. Hoek RM, Ruuls SR, Murphy CA, Wright GJ, Goddard R, Zurawski SM, Blom B, Homola ME, Streit WJ, Brown MH, et al: Down-regulation of the macrophage lineage through interaction with OX2 (CD200). Science 2000, 290:1768-1771.

98. Chitnis T, Imitola J, Wang Y, Elyaman W, Chawla P, Sharuk M, Raddassi K, Bronson RT, Khoury SJ: Elevated neuronal expression of CD200 protects Wlds mice from inflammation-mediated neurodegeneration. Am J Pathol 2007, 170:1695-1712.

99. Neumann H: Control of glial immune function by neurons. Glia 2001, 36:191-199.

100. Wei R, Jonakait GM: Neurotrophins and the anti-inflammatory agents interleukin-4 (IL-4), IL-10, IL-11 and transforming growth factor-beta1 (TGF-beta1) down-regulate T cell costimulatory molecules B7 and CD40 on cultured rat microglia. J Neuroimmunol 1999, 95:8-18.

101. Fukui K, Urano S, Koike T: Releasing factors from mature neurons modulate microglial survival via purinergic receptor activation. Neurosci Lett 2009, 456:64-68.

102. Gehrmann J, Banati RB: Microglial turnover in the injured CNS: activated microglia undergo delayed DNA fragmentation following peripheral nerve injury. J Neuropathol Exp Neurol 1995, 54:680-688.

103. Kuhlmann T, Bitsch A, Stadelmann C, Siebert H, Bruck W: Macrophages are eliminated from the injured peripheral nerve via local apoptosis and 
circulation to regional lymph nodes and the spleen. J Neurosci 2001, 21:3401-3408.

104. Shuman SL, Bresnahan JC, Beattie MS: Apoptosis of microglia and oligodendrocytes after spinal cord contusion in rats. J Neurosci Res 1997 50:798-808.

105. White CA, McCombe PA, Pender MP: Microglia are more susceptible than macrophages to apoptosis in the central nervous system in experimental autoimmune encephalomyelitis through a mechanism not involving Fas (CD95). Int Immunol 1998, 10:935-941.

106. Pais TF, Figueiredo C, Peixoto R, Braz MH, Chatterjee S: Necrotic neurons enhance microglial neurotoxicity through induction of glutaminase by a MyD88-dependent pathway. J Neuroinflammation 2008, 5:43.

107. Eleuteri S, Polazzi E, Contestabile A: Neuroprotection of microglia conditioned media from apoptotic death induced by staurosporine and glutamate in cultures of rat cerebellar granule cells. Neurosci Lett 2008 448:74-78.

108. Moran LB, Graeber MB: The facial nerve axotomy model. Brain Res Brain Res Rev 2004, 44:154-178.

109. Nakajima K, Tohyama Y, Maeda S, Kohsaka S, Kurihara T: Neuronal regulation by which microglia enhance the production of neurotrophic factors for GABAergic, catecholaminergic, and cholinergic neurons. Neurochem Int 2007, 50:807-820.

110. Shih AY, Fernandes HB, Choi FY, Kozoriz MG, Liu Y, Li P, Cowan CM, Klegeris A: Policing the police: astrocytes modulate microglial activation. $J$ Neurosci 2006, 26:3887-3888.

111. Rohl C, Sievers J: Microglia is activated by astrocytes in trimethyltin intoxication. Toxicol Appl Pharmacol 2005, 204:36-45.

112. Ovanesov MV, Ayhan Y, Wolbert C, Moldovan K, Sauder C, Pletnikov MV: Astrocytes play a key role in activation of microglia by persistent Borna disease virus infection. J Neuroinflammation 2008, 5:50

113. von Bernhardi R, Eugenin J: Microglial reactivity to beta-amyloid is modulated by astrocytes and proinflammatory factors. Brain Res 2004, 1025:186-193.

114. Ramirez G, Toro R, Dobeli H, von Bernhardi R: Protection of rat primary hippocampal cultures from A beta cytotoxicity by pro-inflammatory molecules is mediated by astrocytes. Neurobiol Dis 2005, 19:243-254.

115. Aloisi F, Penna G, Cerase J, Menendez Iglesias B, Adorini L: IL-12 production by central nervous system microglia is inhibited by astrocytes. $J$ Immunol 1997, 159:1604-1612.

116. Pyo H, Yang MS, Jou I, Joe EH: Wortmannin enhances lipopolysaccharideinduced inducible nitric oxide synthase expression in microglia in the presence of astrocytes in rats. Neurosci Lett 2003, 346:141-144.

117. Vincent VA, Van Dam AM, Persoons JH, Schotanus K, Steinbusch HW, Schoffelmeer AN, Berkenbosch F: Gradual inhibition of inducible nitric oxide synthase but not of interleukin-1 beta production in rat microglial cells of endotoxin-treated mixed glial cell cultures. Glia 1996, 17:94-102.

118. Rouach N, Calvo CF, Glowinski J, Giaume C: Brain macrophages inhibit gap junctional communication and downregulate connexin 43 expression in cultured astrocytes. Eur J Neurosci 2002, 15:403-407.

119. Rouach N, Calvo CF, Duquennoy H, Glowinski J, Giaume C: Hydrogen peroxide increases gap junctional communication and induces astrocyte toxicity: regulation by brain macrophages. Glia 2004, 45:28-38.

120. Meme W, Calvo CF, Froger N, Ezan P, Amigou E, Koulakoff A, Giaume C: Proinflammatory cytokines released from microglia inhibit gap junctions in astrocytes: potentiation by beta-amyloid. Faseb J 2006, 20:494-496.

121. Rohl C, Armbrust E, Kolbe K, Lucius R, Maser E, Venz S, Gulden M: Activated microglia modulate astroglial enzymes involved in oxidative and inflammatory stress and increase the resistance of astrocytes to oxidative stress in vitro. Glia 2008, 56:1114-1126.

122. McCann MJ, O'Callaghan JP, Martin PM, Bertram T, Streit WJ: Differential activation of microglia and astrocytes following trimethyl tin-induced neurodegeneration. Neuroscience 1996, 72:273-281.

123. Griffin WS: Inflammation and neurodegenerative diseases. Am J Clin Nutr 2006, 83:470S-474S.

124. Davalos D, Grutzendler J, Yang G, Kim JV, Zuo Y, Jung S, Littman DR, Dustin ML, Gan WB: ATP mediates rapid microglial response to local brain injury in vivo. Nat Neurosci 2005, 8:752-758.

125. Verderio C, Matteoli M: ATP mediates calcium signaling between astrocytes and microglial cells: modulation by IFN-gamma. J Immunol 2001, 166:6383-6391.
126. Liu W, Tang Y, Feng J: Cross talk between activation of microglia and astrocytes in pathological conditions in the central nervous system. Life Sci 2011, 89:141-146

127. Giulian D, Baker TJ: Peptides released by ameboid microglia regulate astroglial proliferation. J Cell Biol 1985, 101:2411-2415.

128. Tilleux S, Berger J, Hermans E: Induction of astrogliosis by activated microglia is associated with a down-regulation of metabotropic glutamate receptor 5. J Neuroimmunol 2007, 189:23-30.

129. Savli H, Gulkac MD, Esen N: The effect of stimulated microglia conditioned media on BDNF gene expression of striatal astrocytes: quantification by real-time PCR. Int J Neurosci 2004, 114:1601-1612.

130. Engelhardt B, Ransohoff RM: The ins and outs of T-lymphocyte trafficking to the CNS: anatomical sites and molecular mechanisms. Trends Immunol 2005, 26:485-495.

131. Re F, Belyanskaya SL, Riese RJ, Cipriani B, Fischer FR, Granucci F, RicciardiCastagnoli P, Brosnan C, Stern LJ, Strominger JL, Santambrogio L: Granulocyte-macrophage colony-stimulating factor induces an expression program in neonatal microglia that primes them for antigen presentation. J Immunol 2002, 169:2264-2273.

132. Monsonego A, Imitola J, Zota V, Oida T, Weiner HL: Microglia-mediated nitric oxide cytotoxicity of T cells following amyloid beta-peptide presentation to Th1 cells. J Immunol 2003, 171:2216-2224.

133. Shaked I, Porat Z, Gersner R, Kipnis J, Schwartz M: Early activation of microglia as antigen-presenting cells correlates with $\mathrm{T}$ cell-mediated protection and repair of the injured central nervous system. J Neuroimmunol 2004, 146:84-93.

134. Goldman JE, Reynolds R: A reappraisal of ganglioside GD3 expression in the CNS. Glia 1996, 16:291-295.

135. Kipnis J, Avidan H, Caspi RR, Schwartz M: Dual effect of CD4 + CD25+ regulatory $T$ cells in neurodegeneration: a dialogue with microglia. Proc Natl Acad Sci U S A 2004, 101(Suppl 2):14663-14669.

136. Beers DR, Henkel JS, Zhao W, Wang J, Appel SH: CD4+ T cells support glial neuroprotection, slow disease progression, and modify glial morphology in an animal model of inherited ALS. Proc Natl Acad Sci U S A 2008, 105:15558-15563.

137. Ghasemlou N, Jeong SY, Lacroix S, David S: T cells contribute to lysophosphatidylcholine-induced macrophage activation and demyelination in the CNS. Glia 2007, 55:294-302.

138. Levesque S, Wilson B, Gregoria V, Thorpe LB, Dallas S, Polikov VS, Hong JS, Block ML: Reactive microgliosis: extracellular micro-calpain and microgliamediated dopaminergic neurotoxicity. Brain 2010, 133:808-821.

139. Harry GJ, Kraft AD: Neuroinflammation and microglia: considerations and approaches for neurotoxicity assessment. Expert Opin Drug Metab Toxicol 2008, 4:1265-1277.

140. Knoch ME, Hartnett KA, Hara H, Kandler K, Aizenman E: Microglia induce neurotoxicity via intraneuronal $\mathrm{Zn}(2+)$ release and a $\mathrm{K}(+)$ current surge. Glia 2008, 56:89-96.

141. Qian L, Tan KS, Wei SJ, Wu HM, Xu Z, Wilson B, Lu RB, Hong JS, Flood PM: Microglia-mediated neurotoxicity is inhibited by morphine through an opioid receptor-independent reduction of NADPH oxidase activity. Immunol 2007, 179:1198-1209.

142. Diestel A, Troeller S, Billecke N, Sauer IM, Berger F, Schmitt KR: Mechanisms of hypothermia-induced cell protection mediated by microglial cells in vitro. Eur J Neurosci 2010, 31:779-787.

143. Liang J, Takeuchi H, Jin S, Noda M, Li H, Doi Y, Kawanokuchi J, Sonobe Y, Mizuno T, Suzumura A: Glutamate induces neurotrophic factor production from microglia via protein kinase C pathway. Brain Res 2010, 1322:8-23.

144. Walton NM, Sutter BM, Laywell ED, Levkoff LH, Kearns SM, Marshall GP 2nd, Scheffler B, Steindler DA: Microglia instruct subventricular zone neurogenesis. Glia 2006, 54:815-825.

145. Thored P, Heldmann U, Gomes-Leal W, Gisler R, Darsalia V, Taneera J, Nygren JM, Jacobsen SE, Ekdahl CT, Kokaia Z, Lindvall O: Long-term accumulation of microglia with proneurogenic phenotype concomitant with persistent neurogenesis in adult subventricular zone after stroke. Glia 2009, 57:835-849.

146. McPherson CA, Kraft AD, Harry GJ: Injury-induced neurogenesis: consideration of resident microglia as supportive of neural progenitor cells. Neurotox Res 2011, 19:341-352.

147. Sawada M, Sawada H, Nagatsu T: Effects of aging on neuroprotective and neurotoxic properties of microglia in neurodegenerative diseases. Neurodegener Dis 2008, 5:254-256.

148. Conde JR, Streit WJ: Effect of aging on the microglial response to peripheral nerve injury. Neurobiol Aging 2006, 27:1451-1461. 
149. Luo XG, Ding JQ, Chen SD: Microglia in the aging brain: relevance to neurodegeneration. Mol Neurodegener 2010, 5:12

150. Streit WJ, Sammons NW, Kuhns AJ, Sparks DL: Dystrophic microglia in the aging human brain. Glia 2004, 45:208-212.

151. Wasserman JK, Yang H, Schlichter LC: Glial responses, neuron death and lesion resolution after intracerebral hemorrhage in young vs. aged rats. Eur J Neurosci 2008, 28:1316-1328.

152. Flanary BE, Sammons NW, Nguyen C, Walker D, Streit WJ: Evidence that aging and amyloid promote microglial cell senescence. Rejuvenation Res 2007, 10:61-74.

153. Sugama S, Yang L, Cho BP, DeGiorgio LA, Lorenzl S, Albers DS, Beal MF, Volpe BT, Joh TH: Age-related microglial activation in 1-methyl-4-phenyl1,2,3,6-tetrahydropyridine (MPTP)-induced dopaminergic neurodegeneration in C57BL/6 mice. Brain Res 2003, 964:288-294.

154. Sandhir R, Onyszchuk G, Berman NE: Exacerbated glial response in the aged mouse hippocampus following controlled cortical impact injury. Exp Neurol 2008, 213:372-380.

155. Kyrkanides S, O'Banion MK, Whiteley PE, Daeschner JC, Olschowka JA: Enhanced glial activation and expression of specific CNS inflammationrelated molecules in aged versus young rats following cortical stab injury. J Neuroimmunol 2001, 119:269-277.

156. Kim KY, Ju WK, Neufeld AH: Neuronal susceptibility to damage: comparison of the retinas of young, old and old/caloric restricted rats before and after transient ischemia. Neurobiol Aging 2004, 25:491-500.

157. Lu W, Bhasin M, Tsirka SE: Involvement of tissue plasminogen activator in onset and effector phases of experimental allergic encephalomyelitis. J Neurosci 2002, 22:10781-10789.

158. Bhasin M, Wu M, Tsirka SE: Modulation of microglial/macrophage activation by macrophage inhibitory factor (TKP) or tuftsin (TKPR) attenuates the disease course of experimental autoimmune encephalomyelitis. BMC Immunol 2007, 8:10.

159. El Khoury J, Toft M, Hickman SE, Means TK, Terada K, Geula C, Luster AD: Ccr2 deficiency impairs microglial accumulation and accelerates progression of Alzheimer-like disease. Nat Med 2007, 13:432-438.

160. Gordon S: Alternative activation of macrophages. Nat Rev Immunol 2003, 3:23-35.

161. Gordon S, Taylor PR: Monocyte and macrophage heterogeneity. Nat Rev Immunol 2005, 5:953-964.

162. Wynn TA, Thompson RW, Cheever AW, Mentink-Kane MM: Immunopathogenesis of schistosomiasis. Immunol Rev 2004, 201:156-167.

163. Herber DL, Mercer M, Roth LM, Symmonds K, Maloney J, Wilson N, Freeman MJ, Morgan D, Gordon MN: Microglial activation is required for Abeta clearance after intracranial injection of lipopolysaccharide in APP transgenic mice. J Neuroimmune Pharmacol 2007, 2:222-231.

164. Akiyama H: Inflammatory response in Alzheimer's disease. Tohoku J Exp Med 1994, 174:295-303.

165. Ciaramella A, Bizzoni F, Salani F, Vanni D, Spalletta G, Sanarico N, Vendetti S, Caltagirone C, Bossu P: Increased pro-inflammatory response by dendritic cells from patients with Alzheimer's disease. J Alzheimers Dis 2010, 19:559-572.

166. Rogers J: The inflammatory response in Alzheimer's disease. J Periodontol 2008, 79:1535-1543.

167. Colton CA, Mott RT, Sharpe H, Xu Q, Van Nostrand WE, Vitek MP: Expression profiles for macrophage alternative activation genes in $A D$ and in mouse models of AD. J Neuroinflammation 2006, 3:27.

168. Sawada H, Suzuki H, Nagatsu T, Sawada M: Neuroprotective and neurotoxic phenotypes of activated microglia in neonatal mice with respective MPTPand ethanol-induced brain injury. Neurodegener Dis 2010, 7:64-67.

169. Lai $A Y$, Todd KG: Differential regulation of trophic and proinflammatory microglial effectors is dependent on severity of neuronal injury. Glia 2008, 56:259-270.

170. Hald A, Nedergaard S, Hansen RR, Ding M, Heegaard AM: Differential activation of spinal cord glial cells in murine models of neuropathic and cancer pain. Eur J Pain 2009, 13:138-145.

171. Carson MJ, Reilly CR, Sutcliffe JG, Lo D: Mature microglia resemble immature antigen-presenting cells. Glia 1998, 22:72-85.

172. Ekdahl CT, Kokaia Z, Lindvall O: Brain inflammation and adult neurogenesis: the dual role of microglia. Neuroscience 2009, 158:1021-1029.

173. Aarum J, Sandberg K, Haeberlein SL, Persson MA: Migration and differentiation of neural precursor cells can be directed by microglia. Proc Natl Acad Sci U S A 2003, 100:15983-15988.
174. Luo X, Ge C, Ren Y, Zhou J, Li X, Yan R, Zhang C: BV2 enhanced the neurotrophic functions of mesenchymal stem cells after being stimulated with injured PC12. Neuroimmunomodulation 2009, 16:28-34.

175. Luo XG, Wang H, Zhou J, Yan R, Wu Z, Zhang CD, Wang QS: Beneficial effects of BV2 cell on proliferation and neuron-differentiating of mesenchymal stem cells in the circumstance of injured PC12 cell supernatant. Neurosci Bull 2006 22:221-226.

176. Ekdahl CT, Claasen JH, Bonde S, Kokaia Z, Lindvall O: Inflammation is detrimental for neurogenesis in adult brain. Proc Natl Acad Sci U S A 2003, 100:13632-13637.

177. Monje ML, Toda H, Palmer TD: Inflammatory blockade restores adult hippocampal neurogenesis. Science 2003, 302:1760-1765.

178. Yang F, Liu ZR, Chen J, Zhang SJ, Quan QY, Huang YG, Jiang W: Roles of astrocytes and microglia in seizure-induced aberrant neurogenesis in the hippocampus of adult rats. J Neurosci Res 2010, 88:519-529.

179. Monje ML, Mizumatsu S, Fike JR, Palmer TD: Irradiation induces neural precursor-cell dysfunction. Nat Med 2002, 8:955-962.

180. Battista D, Ferrari CC, Gage FH, Pitossi FJ: Neurogenic niche modulation by activated microglia: transforming growth factor beta increases neurogenesis in the adult dentate gyrus. Eur J Neurosci 2006, 23:83-93.

181. Butovsky O, Ziv Y, Schwartz A, Landa G, Talpalar AE, Pluchino S, Martino G, Schwartz M: Microglia activated by IL-4 or IFN-gamma differentially induce neurogenesis and oligodendrogenesis from adult stem/ progenitor cells. Mol Cell Neurosci 2006, 31:149-160.

182. Aberg MA, Aberg ND, Palmer TD, Alborn AM, Carlsson-Skwirut C, Bang P, Rosengren LE, Olsson T, Gage FH, Eriksson PS: IGF-I has a direct proliferative effect in adult hippocampal progenitor cells. Mol Cell Neurosci 2003, 24:23-40.

183. Choi YS, Cho HY, Hoyt KR, Naegele JR, Obrietan K: IGF-1 receptor-mediated ERK/MAPK signaling couples status epilepticus to progenitor cell proliferation in the subgranular layer of the dentate gyrus. Glia 2008, 56:791-800.

184. Butovsky O, Hauben E, Schwartz M: Morphological aspects of spinal cord autoimmune neuroprotection: colocalization of T cells with B7-2 (CD86) and prevention of cyst formation. Faseb J 2001, 15:1065-1067.

185. Buckwalter MS, Yamane M, Coleman BS, Ormerod BK, Chin JT, Palmer T, Wyss-Coray T: Chronically increased transforming growth factor-beta1 strongly inhibits hippocampal neurogenesis in aged mice. Am J Pathol 2006, 169:154-164

186. Ogita K, Nishiyama N, Sugiyama C, Higuchi K, Yoneyama M, Yoneda Y: Regeneration of granule neurons after lesioning of hippocampal dentate gyrus: evaluation using adult mice treated with trimethyltin chloride as a model. J Neurosci Res 2005, 82:609-621.

187. Harry GJ, McPherson CA, Wine RN, Atkinson K, Lefebvre d'Hellencourt C: Trimethyltin-induced neurogenesis in the murine hippocampus. Neurotox Res 2004, 5:623-627.

188. Kuhn HG, Dickinson-Anson H, Gage FH: Neurogenesis in the dentate gyrus of the adult rat: age-related decrease of neuronal progenitor proliferation. J Neurosci 1996, 16:2027-2033.

189. Knoth R, Singec I, Ditter M, Pantazis G, Capetian P, Meyer RP, Horvat V, Volk B, Kempermann $\mathrm{G}$ : Murine features of neurogenesis in the human hippocampus across the lifespan from 0 to 100 years. PLoS One 2010, 5:e8809.

190. Zhu C, Qiu L, Wang X, Xu F, Nilsson M, Cooper-Kuhn C, Kuhn HG, Blomgren $\mathrm{K}$ : Age-dependent regenerative responses in the striatum and cortex after hypoxia-ischemia. J Cereb Blood Flow Metab 2009, 29:342-354.

191. Ransohoff RM, Kivisakk P, Kidd G: Three or more routes for leukocyte migration into the central nervous system. Nat Rev Immunol 2003, 3:569-581.

192. Ziv Y, Finkelstein A, Geffen Y, Kipnis J, Smirnov I, Shpilman S, Vertkin I, Kimron M, Lange A, Hecht T, et al: A novel immune-based therapy for stroke induces neuroprotection and supports neurogenesis. Stroke 2007, 38:774-782.

193. Ziv Y, Ron N, Butovsky O, Landa G, Sudai E, Greenberg N, Cohen H, Kipnis J, Schwartz M: Immune cells contribute to the maintenance of neurogenesis and spatial learning abilities in adulthood. Nat Neurosci 2006, 9:268-275.

doi:10.1186/2047-9158-1-9

Cite this article as: Luo and Chen: The changing phenotype of microglia from homeostasis to disease. Translational Neurodegeneration 2012 1:9. 